\title{
Medição de perda e produtividade de argamassa industrializada no serviço de revestimento de fa- chada
}

Caetano, A. S.

Escola Politécnica de Pernambuco Universidade de Pernambuco 50.720-001 - Recife, Brasil alissoncaetanodasilva@hotmail.com
Casado, A. L. L. J.

Escola Politécnica de Pernambuco

Universidade de Pernambuco

50.720-001 - Recife, Brasil

Resumo A medição do desempenho da execução do revestimento de argamassa de fachada deve merecer especial atenção na construção de edifícios, pois representa parcela expressiva do custo total e condiciona o prazo da obra. Dentro desse contexto, este projeto de pesquisa tem como principal objetivo monitorar o desperdício de argamassa e a produtividade da mão de obra na execução do revestimento de argamassa de fachadas de edificios.

Abstract Performance measurement of the coating run mortar shell should deserve special attention in building construction, as it represents a significant portion of the total cost of the term and conditions of the work. Within this context, this research project has as main objective to monitor the waste of mortar and productivity of labor in the execution of mortar lining of building facades. 


\section{Introdução}

Este projeto de iniciação científica faz parte de um projeto de pesquisa que está associado a uma Dissertação de mestrado do Programa de Pós-Graduação em Engenharia Civil da POLI/UPE. O tema inicialmente proposto focaria a "concretagem de estrutura de concreto armado"; porém, adequando ao macro projeto, o foco foi direcionado para o tema de "revestimento de argamassa de fachada" ficando preservados a metodologia e os objetivos.

A medição de desempenho na indústria da construção é uma prática relativamente recente, tendo recebido forte impulso pela implantação e certificação de sistemas de gestão da qualidade pelas empresas construtoras (DUARTE, 2011). As normas NBR ISO 9001:2008 e do Sistema de Avaliação da Conformidade de Empresas de Serviços e Obras da Construção Civil (SiAC) do Programa Brasileiro de Qualidade e Produtividade no Habitat (PBQP-H) contem exigências específicas relativas à medição de desempenho. Os sistemas de medição de desempenho fornecem informações essenciais para $o$ planejamento e controle dos processos gerenciais e o monitoramento dos objetivos e metas estratégicas da empresa.

\section{Material de estudo}

Como componente da envoltória do edifício, o revestimento de emboço de fachada tem uma estreita relação com os mais diversos subsistemas da edificação, como, por exemplo, estrutura de concreto armado e alvenaria de vedação. Além disso, o emboço possui funções que o tornam de vital importância para o edifício, não só esteticamente, mais também com relação ao desempenho deste, mais que regularizar a fachada, o emboço veda e protege o edifício, inibindo a penetração de agentes agressivos.

A importância das funções exercidas pelo revestimento de emboço de fachada, bem como a influência que representa nos custos da obra, remetem a necessidade de estudar a mão-de-obra envolvida na execução deste serviço.

Em se tratando do desperdício da argamassa parcialmente ou totalmente produzida fora do canteiro para emboço ou massa única, Agopyan et al. (1998) apresentam os resultados de pesquisa em 04 obras, cujo valor médio foi de 99\%; enquanto, o mínimo de desperdício foi de 5\% e o máximo atingiu 209\%. Percebeu-se uma dispersão muito elevada dos resultados, remetendo a necessidade de estudos mais detalhados para a obtenção de dados condizentes com a realidade de cada situação.

Diante disto, verifica-se a importância do estudo do desperdício de argamassa e da produtividade da mão-de- obra envolvida na execução do revestimento de argamassa de fachada, já que este serviço envolve a execução de subetapas, constitui funções importantes e custos representativos para a edificação como um todo.

\section{Metodologia}

Etapa 01 - levantamento bibliográfico: identificando a literatura sobre medição de desempenho; indicadores de consumo, perdas e produtividade; benchmarking, através de consulta: artigos de revistas nacionais e internacionais, normas, sites na internet de institutos de pesquisa e associações de construção. Essa fase foi de grande importância pois aprendi muito sobre o serviço de emboço de fachada , onde existe uma grande relação e importância para a vida útil da construção o revestimento externo desempenha. Outro grande aprendizado que pude ganhar foi conhecer melhor um indicador de produtividade chamado RUP (razão unitária de produção), onde ele é a razão então a quantidade de horas trabalhadas pela quantidade de serviço feito nesse intervalo de tempo. Quanto maior for o valor pior é a produtividade.

Etapa 02: análise de indicadores de desempenho, definição de metodologia de coleta de dados: conhecimento e definição do sistema de medição de desempenho. A metodologia empregada para medir as perdas de argamassa industrializada e a produtividade foi antes discutida em são Paulo, são usadas planilhas bem simples para que qualquer estagiário ou encarregado treinado possa também preenche-las. Nelas colocamos as quantidades de serviço da semana medida $\mathrm{em}^{2}$, as horas trabalhadas de cada pedreiro e servente, o s estoque de argamassa presente na obra e o que chegou durante a semana. Assim com esses dados pode-se calcular a as RUPs e perdas de argamassa.

Etapa 03 - monitoramento dos indicadores: acompanhamento sistemático dos resultados gerados em 03 obras para a análise, a comparação e a identificação das melhores práticas. Essa é a presente etapa se encontra o projeto de pesquisa. Nela se põem em prática o que foi dito anteriormente. Acabamos de finalizar a primeira obra, partindo para outra.

Etapa 04: identificação e caracterização das melhores práticas: descrição detalhada das melhores práticas (produtos, serviços e métodos de trabalho), com o propósito de melhoria organizacional que conduz à superioridade competitiva.

Etapa 05: diretrizes para a adoção das melhores práticas: estabelecimento das principais ações necessárias que 
promovam maiores possibilidades de sucesso na implantação das melhores práticas no serviço de revestimento de argamassa de fachada.

\section{Resultados obtidos}

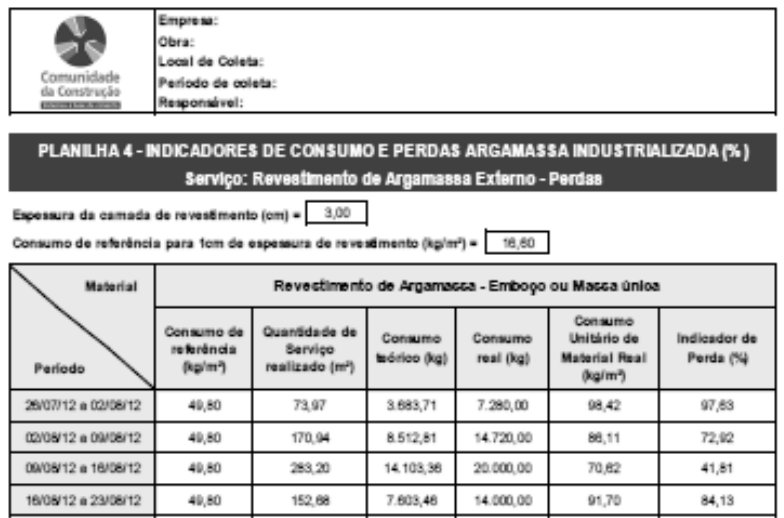

Fig 1. Resultados de perdas

\begin{tabular}{|c|c|c|c|c|}
\hline \multirow[b]{2}{*}{$\begin{array}{l}\text { Semanas coletadas } \\
\text { (Data) }\end{array}$} & \multicolumn{4}{|c|}{ Emboco ou masea unica (mi) } \\
\hline & $\mathrm{QS}_{\mathrm{sm}}(\mathrm{m})$ & Hhan direta & RUPPenem dilreta & FuPC $\mathrm{C}_{\mathrm{pen}}$ dilreta \\
\hline $26 / 07 / 12$ a $02 / 08 / 12$ & 73,12 & 63,00 & 0,86 & 0,86 \\
\hline CQ/DQ/12 a 09/D\&/12 & 170,94 & 133,00 & 0,78 & 0,80 \\
\hline $09 / 08 / 12$ a $16 / 08 / 12$ & 283,00 & 176,00 & 0,62 & 0,71 \\
\hline $16 / 08 / 12$ a $23 / 0812$ & 152,68 & 88,00 & 0,58 & 0,68 \\
\hline Total & 679,74 & 460,00 & 0,68 & 0,68 \\
\hline
\end{tabular}

Fig 2. Resultaddos de produtividade

\begin{tabular}{|c|c|c|c|c|}
\hline \multirow[b]{2}{*}{$\begin{array}{c}\text { Semanas coletadas } \\
\text { (Data) }\end{array}$} & \multicolumn{4}{|c|}{ Emboço ou masea unlca (m²) } \\
\hline & $Q S_{m}(m)$ & Hithen direta & RUPsen direta & RUPGram direta \\
\hline $26 / 107 / 12$ a $02 / 08 / 12$ & 73,12 & 63,00 & 0,86 & 0,86 \\
\hline $02 / 08 / 12$ a $09 / 08 / 12$ & 170,94 & 106,00 & 0,62 & 0,69 \\
\hline $09 / 08 / 12$ a $16 / 08 / 12$ & 283,00 & 132,00 & 0,47 & 0,57 \\
\hline $16 /, 08 / 12$ a 2310812 & 152,68 & 44,00 & 0,29 & 0,51 \\
\hline Total & 679,74 & 345,00 & 0,51 & 0,51 \\
\hline
\end{tabular}

Fig 2. Resultados de produtividade

Nota-se com esta tabela que se chega até termos umas perda de quase $100 \%$ ou seja o dobro orçado pela construtora. Por isso é de grande importância ter um monitoramento severo do serviço de argamassa industrializada.

A partir dos resultados obtidos se teve uma idéia de como é grande a perda de argamassa industrializada e o quanto a mão de obra ainda está longe do esperado para uma eficiente produção.

\section{Conclusão}

Esse estudo foi de grande importância, pois já se sabe que a forma mais certa de controle é o monitoramento e com essa ferramenta apresentada as construtoras terão um grande dispositivo no monitoramento da produtividade e principalmente da perda de um material tão importante que é a argamassa industrializada.

E como foi visto nos resultados ainda esta longe o que é previamente orçado para a obra com a realidade, e estas ferramentas de controle facilitarão demais a possibilidade de saber onde esta a deficiência da produtividade e verificar as perdas e assim combatê-las.

\section{Referências}

[1] AGOPYAN, V.; SOUZA, U.E.L.; PALIARI, J.C.; ANDRADE, A.C. Alternativas para redução do desperdício de materiais nos canteiros de obra, 1998. Disponível em: http://habitare.infohab.org.br/pdf/publicacoes/arquivos/104.pdf.

Acesso em: 01 fev. 2009.

[2] BAÍA, L.L.M.; SABBATINI, F.H. Projeto e execução de revestimento de argamassa. São Paulo: O Nome da Rosa, 2000.

[3] BARKOKEBAS JUNIOR, B.; LORDSLEEM JR., A.C.; SILVA, B. M. V.; DUARTE, C. M. M. Sistemas de gestão em segurança e saúde do trabalho e de gestão da qualidade na construção civil. Recife: EDUPE, 2009. v. 1. 126 p.

[4] CAVALCANTI, R.F.V. Uma investigação sobre medidas de desempenho utilizadas pelas empresas de construção civil, subsetor edificações, na região metropolitana de Recife. 110p. Dissertação (Mestrado) - Programa multiinstitucional UnB/UFPB/UFPE/URFN. Recife, 2004.

[5] COSTA, D.B.. Diretrizes para concepção, implementação e uso de sistemas de indicadores de desempenho para empresas de construção civil. 176f. Dissertação (Mestrado) - Escola de Engenharia, Universidade Federal do Rio Grande do Sul. Porto Alegre, 2003.

[6] COSTA, D.B. et al. Sistema de indicadores para benchmarking na construção civil: manual de utilização. Porto Alegre: UFRGS/PPGEC/NORIE, 2005.

[7] DUARTE, C.M. Desenvolvimento de sistema de indicadores para benchmarking em empresas de construção civil. 250 p. Dissertação (Mestrado) - 
Universidade de Pernambuco. Recife, 2011. 